\title{
The influence of hypoxic physical activity on cfDNA as a new marker of vascular inflammation
}

\author{
Andrzej Pokrywka ${ }^{1}$, Agnieszka Zembron-Lacny ${ }^{1}$, Katarzyna Baldy-Chudzik², Joanna Orysiak ${ }^{3}$, \\ Dariusz Sitkowski ${ }^{4}$, Maciej Banach ${ }^{5}$
}

\author{
${ }^{1}$ Department of Applied and Clinical Physiology, University of Zielona Gora, \\ Zielona Gora, Poland \\ 2Department of Molecular Biology of Biological Sciences, University of Zielona Gora, \\ Zielona Gora, Poland \\ ${ }^{3}$ Department of Physiological Nutrition, Institute of Sport, Warsaw, Poland \\ ${ }^{4}$ Department of Physiology, Institute of Sport, Warsaw, Poland \\ ${ }^{5}$ Department of Hypertension, Chair of Nephrology and Hypertension, \\ Medical University of Lodz, Lodz, Poland
}

Submitted: 23 November 2014

Accepted: 12 December 2014

Arch Med Sci 2015; 11, 6: 1156-1163

DOI: 10.5114/aoms.2015.56341

Copyright (c) 2015 Termedia \& Banach

\section{Abstract}

The phenomenon of circulating cell-free DNA (cfDNA) is important for many biomedical disciplines including the field of exercise biochemistry and physiology. It is likely that cfDNA is released into the plasma by apoptosis of endothelial cells and circulating endothelial progenitor cells (EPCs), and/ or by NETosis of immune cells induced by strenuous exercise. Increases of cfDNA are described to be a potential hallmark for the overtraining syndrome, and might be related to aseptic vascular inflammation in athletes. Yet, the relevance of systemic inflammation and cfDNA with endothelial dysfunction in athletes still remains unclear. In this review article, we provide a current overview of exercise-induced cfDNA release to the circulation with special emphasis on its relationship with apoptosis and NETosis and the effect of hypoxic physical activity on vascular inflammation in athletes.

Key words: apoptosis, NETosis, cytokines, overtraining.

\section{Introduction}

It has been shown that vascular endothelial dysfunction precedes the development of arteriosclerosis, and thereafter plays an important role in its progression. Therefore, preservation or recovery of endothelial function is important to inhibit the development of cardiovascular events [1]. Several biomarkers have been proposed to investigate endothelial dysfunction, including insulin resistance, homocysteinemia, inflammatory cytokines, oxidized lipoproteins LDL and HDL, reactive oxygen and nitrogen species, vasodilators and vasoconstrictors (Table I) [2-21]. Recent studies have also suggested that dysfunctional HDL might be very effective and predictive biomarker of endothelial impairment as well as cardiovascular risk [22-26].

The newest studies demonstrate that cell-free DNA (cfDNA) could serve as an auxiliary biomarker of vascular endothelial dysfunction and cardiometabolic risk assessment $[6,27,28]$. The mechanisms of the occurrence of cfDNA fragments in blood under normal and pathological conditions are not yet fully understood. The sequence analysis of circulat-

\author{
Corresponding author: \\ Andrzej Pokrywka \\ Department of Applied \\ and Clinical Physiology \\ University of Zielona Gora \\ 26 Zyty St \\ 65-417 Zielona Gora, Poland \\ Phone/fax: +48 683283105 \\ E-mail: a.pokrywka@wlnz. \\ uz.zgora.pl
}


Table I. Changes in biomarkers of vascular endothelial dysfunction

\begin{tabular}{|c|c|c|}
\hline Markers & $\begin{array}{l}\text { Direction } \\
\text { of change }\end{array}$ & References \\
\hline Adiponectin & $\downarrow$ & {$[2-4]$} \\
\hline $\begin{array}{l}\text { Adhesion molecules: vascular cell adhesion molecule (VCAM), intercellular } \\
\text { adhesion molecule (ICAM), P-selectin, E-selectin }\end{array}$ & $\uparrow$ & [5] \\
\hline Circulating cell-free DNA (cfDNA) & $\uparrow$ & [6] \\
\hline Circulating microRNA (miRNA) & $\uparrow$ & [7] \\
\hline Endothelial progenitor cells (EPCs) & $\downarrow$ & {$[8,9]$} \\
\hline $\begin{array}{l}\text { Endogenous inhibitors of nitric oxide synthase (NOS): asymmetric } \\
\text { dimethyl-arginine (ADMA) }\end{array}$ & $\uparrow$ & [10] \\
\hline Homocysteine (Hcy) & $\uparrow$ & [11] \\
\hline Insulin resistance & $\uparrow$ & [12] \\
\hline 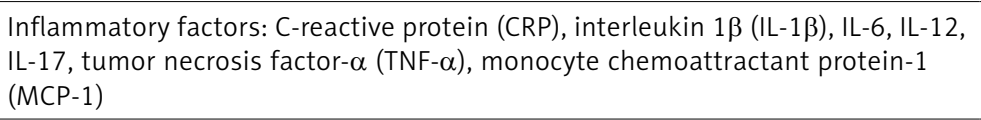 & $\uparrow$ & {$[6,9,13-15]$} \\
\hline Lipoproteins LDL, oxidized LDL (oxLDL) and oxidized HDL (oxHDL) & $\uparrow$ & {$[6,16,17]$} \\
\hline Peroxynitrite (ONOO-) & $\uparrow$ & {$[9,18,19]$} \\
\hline $\begin{array}{l}\text { Thrombotic hemostatic factors: plasminogen activator inhibitor-1 (PAl-1), tissue } \\
\text { plasminogen activator (TPA), von Willebrand factor, thrombomodulin }\end{array}$ & $\uparrow$ & {$[9,20]$} \\
\hline $\begin{array}{l}\text { Vasoconstrictors: endothelin, thromboxane A2, reactive oxygen and nitrogen } \\
\text { species (RONS) }\end{array}$ & $\uparrow$ & {$[9,19,21]$} \\
\hline Vasodilators: nitrite and nitrate, 6-keto PGF1 $\alpha$ & $\uparrow$ & [9] \\
\hline
\end{tabular}

ing DNA in normal human plasma demonstrated that cfDNA fragments are derived from apoptotic cells but not from necrotic cells. The mean values of cfDNA length were $\sim 180 \mathrm{bp}$ in the culture supernatant of apoptotic cells, while DNA fragments larger than $\sim 10,000$ bp are observed in the culture of cells undergoing necrosis. Their $5^{\prime}$ and $3^{\prime}$ ends were rich in cytosine and guanidine, respectively, and they presented in the $5^{\prime}$ end characteristic (protruding) forms of double-stranded DNA. The cfDNA concentrations in normal plasma samples were $3.6-5.0 \mathrm{ng} / \mathrm{ml}$ [29]. The cfDNA fragments apparently circulate as nucleoprotein complexes, but the main part of cfDNA is found adsorbed to the surface of blood cells in healthy individuals [30].

A novel fascinating explanation of how DNA can actively be released under inflammatory conditions has recently become apparent by the discovery of an evolutionarily highly conserved firstline defense mechanism that allows neutrophils to expel their DNA in response to infectious or endogenous factors, thereby forming a meshwork of chromatin and proteins, termed neutrophil extracellular traps (NETs). Accumulating evidence indicates that formation of NETs plays a pivotal role in the immune response to both pathogens and physical exercise [27].

Strenuous exercise, which consists of high-force eccentric exercises interspersed with long-duration endurance exercises at mild- to moderate-intensity work or regular high-intensity workouts, induces a slow and constant release of cfDNA.
During incremental treadmill running the capillary cfDNA concentrations increased nearly parallel to the lactate values. The values correlated best with heart rate and energy expenditure, followed by oxygen consumption and lactate levels [24]. After chronic excessive resistance exercise, cfDNA level increased in proportion to muscle damage (CK increase) and systemic inflammation (hsCRP increase), suggesting that plasma DNA may be a sensitive marker for overtraining-induced inflammation [30-33].

It is likely that cfDNA is released into the plasma by apoptosis of endothelial cells and circulating endothelial progenitor cells, and/or by NETosis of immune cells induced by strenuous exercise [34]. According to Angeli et al. [35] the generation of pro-inflammatory and pro-apoptotic mediators disturbs vascular endothelial activity. However, the relevance of cfDNA with inflammation and endothelium function in athletes still remains unclear. It is well known that marathon, rowing, soccer, tennis, handball and basketball cause activation of immune cells, which synthesize large quantities of pro-inflammatory and pro-apoptotic cytokine tumor necrosis factor- $\alpha$ (TNF- $\alpha$ ) that can be responsible for vascular endothelial dysfunction [1, 36-43].

In this review article, we provide a current overview of exercise-induced cfDNA release to the circulation with special emphasis on its relationship with apoptosis and NETosis and the effect of hypoxic training on vascular inflammation in athletes. 


\section{Physical activity and vascular inflammation}

Physical activity has significant beneficial effects on overall health, and especially on cardiovascular morbidity and mortality. Regular physical activity significantly attenuates the atherosclerotic process by reducing atherosclerotic risk factors, retarding arterial wall aging, delaying development of endothelial dysfunction and preserving vascular function. Furthermore, regular physical activity reduces vascular oxidative stress, increases NO production via endothelial NOS (eNOS), modifies the lipid profile [44-46], inhibits the production of pro-inflammatory and pro-apoptotic cytokine TNF- $\alpha$ [47], and also decreases both oxidative stress and the circulating concentrations of ADMA [48]. It is stressed that observations were performed on healthy non-active subjects or patients with coronary artery disease $[49,50]$. It is still not known how pro-inflammatory and pro-apoptotic molecules affect endothelial cells' activity in highly trained subjects.

There were a few observations concerning changes in markers of endothelial activity in elite athletes following intense training periods or after finishing their sport career. It is known that the detraining period induces a rapid increase in total cholesterol (TC) and lipoprotein LDL, which elevates the risk of cardiovascular disease [51]. In our recent project, a high level of total cholesterol in $43 \%$ of elite Greco-Roman wrestlers was observed. The average concentrations of serum total cholesterol, lipoprotein HDL and LDL as well as triglycerides were 193, 51, 120 and $108 \mathrm{mg} / \mathrm{dl}$, respectively (unpublished data). We do not know whether the observed changes in lipid profile are temporary, whether they are related to endothelial dysfunction, and what the health implications for the future are. Maron et al. [52] estimated that $18.5 \%$ of incidents of sudden death in young athletes ( $<35$ years old) were related to vascular endothelial dysfunction and atherosclerotic coronary artery disease. According to Suarez-Mier et al. [53], the sports most frequently associated with sudden death were cycling (29\%), soccer (25.5\%), running (8.9\%) and gymnastics (6.5\%). Approximately $70 \%$ cases were not related to some personal pathological antecedents or familial sudden deaths. De Van and Seals [54] observed that masters endurance athletes demonstrate a more favorable arterial phenotype and lower risk of CVD compared with untrained middle-aged and older adults. In contrast, masters athletes for whom training and competitive sport require primarily or exclusively intensive resistance muscle activities exhibit a less favorable arterial function-structure profile. The differences in arterial properties between masters athletes participating in endurance sports vs. resistance training-requir- ing sports are likely explained by differences in the intravascular mechanical forces generated during these activities. Agrotou et al. [55] demonstrated that the type of anaerobic exercise, e.g. weightlifting, is an important determinant of subclinical atherosclerosis such as intima-media thickness and flow-mediated dilation.

\section{Apoptosis and vascular inflammation}

Vascular inflammation is an early marker of endothelial dysfunction prior to the development of structural changes and clinical symptoms, contributes to the progression of atherosclerosis, and increases the risk of coronary events. Studies over the past year have demonstrated the significance of inflammation in endothelial apoptosis [56-58].

In athletes, endothelial apoptosis can be triggered through several pathways. One of them can be induced by the binding of TNF- $\alpha$ to one or more of the extracellular receptors of the tumor necrosis factor receptor (TNFRs) superfamily located on the surface of macrophages, T lymphocytes and endothelial cells. The binding of this ligand to its receptors ultimately leads to the activation of a specific set of proteases crucial for the execution of apoptosis. These proteases are collectively referred to as caspases, and they are activated by proteolytic cleavage. Caspases have the ability to cleave and activate other caspases in a "cascade-like" fashion. This serves as an efficient and potent mechanism for amplifying the cell death signal. Ultimately, caspase activation is responsible for the biochemical breakdown of cytosolic and nuclear targets leading to the distinct morphological features of apoptosis. Recruitment of procaspase 8 to the plasma membrane results in feedforward recruitment of more procaspase- 8 proteins. This caspase- 8 accumulation forms a death-inducing signaling complex at the plasma membrane, resulting in caspase- 8 activation. Activated caspase- 8 can then directly cleave and activate caspase-3. Caspase- 3 exerts its apoptotic effect by cleaving key structural proteins of the plasma membrane and nuclear envelope, leading to the structural breakdown of the cell. However, this enzyme mediates its primary effects within the nucleus of the cell. Activated caspase- 3 translocates from the cytosol to the nucleus, where it cleaves and deactivates an inhibitor of caspase-activated DNase. This releases caspase-activated DNase, and endonuclease, enabling the cleavage of genomic DNA. This DNA fragmentation is one of the hallmark morphological features of apoptosis [34, 59].

In athletes, a high concentration of TNF- $\alpha$ can also induce endothelial apoptosis through disturbance of the equilibrium between eNOS and inducible NOS (iNOS) activities, resulting in pro-apoptotic NO activity, and finally disturbanc- 
es in vascular endothelial activity which precedes the development of arteriosclerosis [19, 58]. The excess NO reacts with the superoxide anion to produce peroxynitrite $\left(\mathrm{ONOO}^{-}\right)$by 1000000 -fold. $\mathrm{ONOO}^{-}$in turn-can "uncouple" eNOS to become a dysfunctional superoxide-generating enzyme that contributes to vascular oxidative stress. Oxidative stress and endothelial dysfunction can promote atherogenesis. Without superoxide, the formation of $\mathrm{ONOO}^{-}$by the reaction of $\mathrm{NO}$ with oxygen is minimal. Nitric oxide and superoxide do not even have to be produced within the same cell to form peroxynitrite, because NO can so readily move through membranes and between cells [19].

Athletes have demonstrated significantly higher levels of reactive oxygen and nitrogen species [60] and TNF- $\alpha$ [35-41], which can serve as predictors of overtraining-induced inflammation [37, 43]. Survey research involving endurance athletes who completed monocycle training indicated a rate of overtraining syndrome of approximately 10\% (range: 7-21\%) [61].

\section{Netosis and vascular inflammation}

Recently, a novel mechanism of cfDNA release at inflammation sites was described. Upon activation, neutrophils release NETs composed of DNA fibers decorated with granular proteins. Neutrophil extracellular traps are produced by neutrophils and other immune cells, in contact with pathogens, a variety of host factors such as activated platelets, inflammatory mediators or reactive oxygen and nitrogen species (Table II) [62-76].

Neutrophil extracellular traps are the results of a unique form of cell death that morphologically is characterized by the loss of intracellular membranes before the integrity of the plasma membrane is compromised. To release NETs, activated neutrophils undergo dramatic morphological changes. Minutes after activation, they flatten and firmly attach to the substratum. During the next hour, the nucleus loses its lobules, the chromatin decondenses, and the inner and outer nuclear membranes progressively detach from each other. Concomitantly, the granules disintegrate. After $1 \mathrm{~h}$, the nuclear envelope disaggregates into vesicles and the nucleoplasm and cytoplasm form a homogeneous mass. Finally, the cells round up and seem to contract until the cell membrane ruptures and the interior of the cell is ejected into the extracellular space, forming NETs. Notably, despite the intermixing of cellular compartments, during the last phase of NETosis, < 30 proteins are present in NETs. Most of them originate from granules, a few are from the nucleus, and cytoplasmic NET components are rare. NETosis is morphologically quite different from apoptosis and necrosis (Figure 1) $[62,70,77,78]$.

Beiter et al. [27] were the first to demonstrate evidence of exhaustive exercise-induced release of NETs. Their observation opened a new avenue to understand exercise immunology. The authors stressed that future work is necessary to explain whether this phenomenon is a remnant of the ancient human fight-or-flight response or whether NETs represent a fundamental layer of the immune response to exercise.

\section{Physical activity in hypoxia and endothelial repair}

Endothelial cell injury initiates regenerative processes. The first step is the mobilization of

Table II. Exogenous and endogenous factors which stimulate the formation of NETs

\begin{tabular}{|c|c|}
\hline Factors & References \\
\hline Calcium ions $\mathrm{Ca}^{2+}$ & [63] \\
\hline $\begin{array}{l}\text { Glucose oxidase }(\mathrm{GOx}) \text { catalyzes the oxidation of } \beta \text {-D-glucose to gluconic acid with simultaneous } \\
\text { production of } \mathrm{H}_{2} \mathrm{O}_{2}\end{array}$ & {$[64]$} \\
\hline $\begin{array}{l}\text { Granulocyte-macrophage colony-stimulating factor (GM-CSF) + C5a } \\
\text { Granulocyte-macrophage colony-stimulating factor (GM-CSF) + LPS }\end{array}$ & {$[65,66]$} \\
\hline 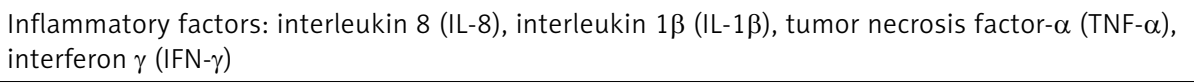 & {$[63,66,67]$} \\
\hline $\begin{array}{l}\text { Lipopolysaccharide (LPS) } \\
\text { Lipophosphoglycan (LPG) }\end{array}$ & {$[68-70]$} \\
\hline M1-protein-fibrinogen complex & [71] \\
\hline Panton-Valentine leukocidin (PVL) & [72] \\
\hline Pathogens: bacteria, fungi, viruses, parasites & {$[68-70,72]$} \\
\hline Platelet activating factor (PAF) & [73] \\
\hline Reactive oxygen and nitrogen species: hydrogen peroxide $\left(\mathrm{H}_{2} \mathrm{O}_{2}\right)$, nitric oxide (NO) & [74] \\
\hline Statins: lovastatin, simvastatin, fluvastatin and mevastatin & [75] \\
\hline Platelet via toll-like receptor 4 (TLR-4) & {$[76]$} \\
\hline
\end{tabular}




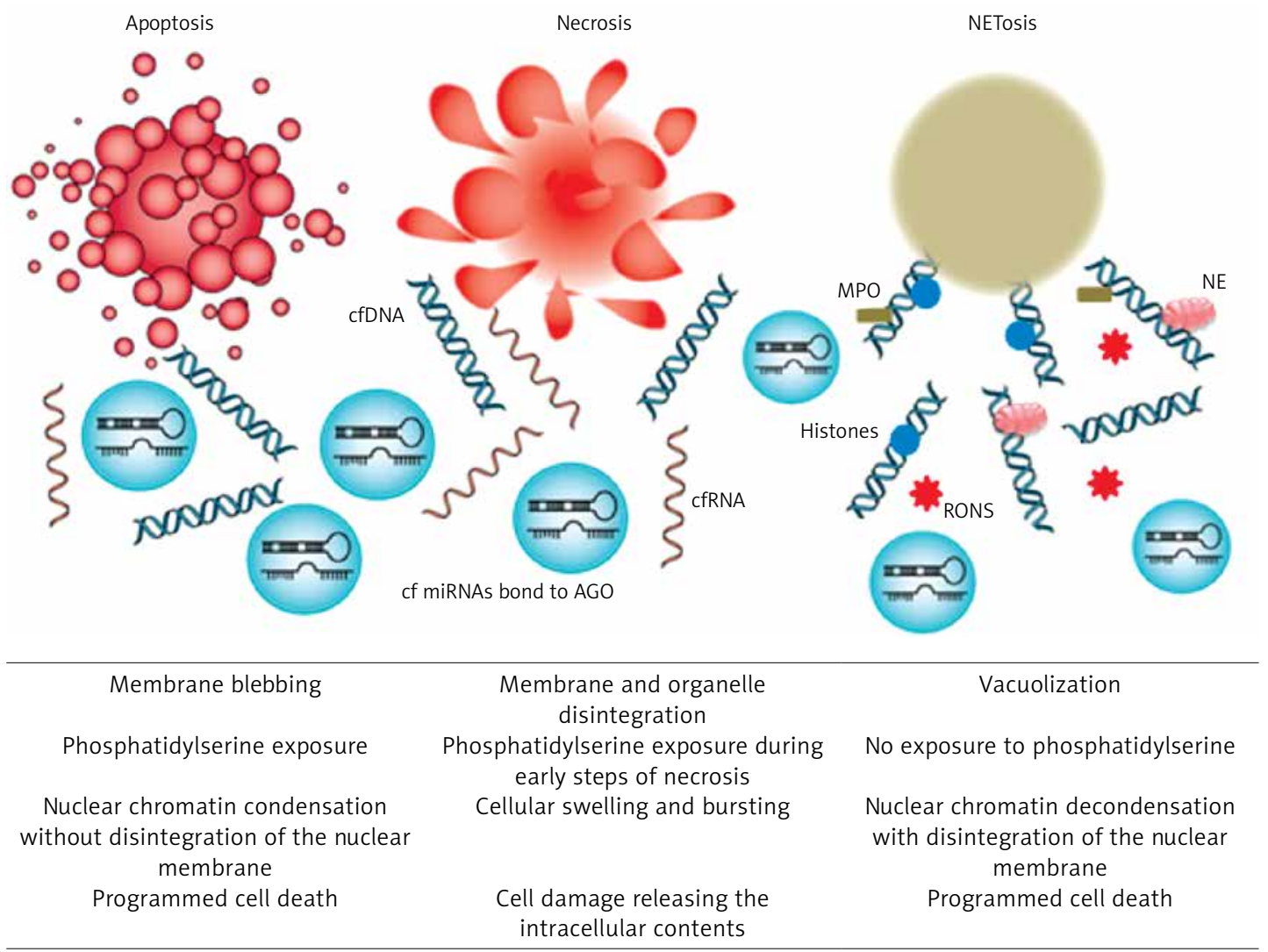

Figure 1. Schematic representation and differences between apoptosis, necrosis and NETosis

cfDNA - Circulating cell free DNA, cfRNA - circulating cell free RNA, AGO - Argonaute protein, MPO - myeloperoxidase, NE - neutrophil elastase, RONS - reactive oxygen and nitrogen species, miRNAs - short noncoding RNAs (19-25 nucleotides) that modulate gene expression at the posttranscriptional level and play important roles in a wide range of physiological and pathological processes $[62,77,78]$

endothelial progenitor cells (EPCS) from the bone marrow into peripheral blood, which is followed by the recruitment of EPCs to the site of vascular injury. Decreased numbers of circulating EPCS are seen in patients with coronary risk factors and reflect senescence, endothelial dysfunction, impaired vascular repair, and increased cardiovascular events. Enhancement of EPCs is considered one of the most promising therapeutic alternatives for cardiovascular disease. The process of EPC mobilization leads to accelerated re-endothelialization, successfully achieved by erythropoietin and other growth factors [1].

Endothelial progenitor cells count is related to age and health status, and increases in response to physical exercise $[8,79-83]$ and hypoxia [84, 85] that occurs at high altitude. Ciulla et al. [84] observed in the Himalayas that high-altitude hypoxia and exercise oxygen demands are strong stimuli for clonogenic endothelial cell activation and activity, as shown by the increase in the number of EPCs. However, Mancuso et al. [86] found that circulating hematopoietic stem cells, circulating endothelial cells and EPC counts significantly decreased in 15 mountain trekkers after 12 days spent at $>3000 \mathrm{~m}$. Strenuous exercise with expo- sure to hypobaric hypoxia can be dangerous for athletes with endothelial dysfunction [87].

Physical training in hypoxia (hypobaric hypoxia) has been used for decades by Olympic and professional athletes to increase endurance, strength and speed, avoid fatigue and improve recovery [88, 89]. Recently, intermittent hypoxic training (IHT, normobaric hypoxia) was introduced into sport practice. Intermittent hypoxic training is a method by which athletes receive exposure to short bouts of severe hypoxia $\left(9-12 \% \mathrm{O}_{2}\right)$, interspersed with periods of normal air. The studies reported substantial improvements in sea level endurance and anaerobic performance after IHT at rest or during exercise. These enhancements suggest that IHT may be suitable for improving performance in high intensity team sports. Beside the effects of the hypoxic stimuli on exercise performance, there is recent evidence that intermittent hypoxic training or therapy (IHT) might be beneficial for endothelial cell activity $[89,90]$.

It is still not known whether normobaric hypoxia affects the circulating EPC number and whether IHT can reduce vascular inflammation in athletes. We observed a significant decrease in total cholesterol (by 10-15\%) and its classes following IHT (unpub- 
lished data). According to the consensus statement of the European Society of Cardiology, a decrease in serum cholesterol by $10 \%$ results in a reduction of cardiac artery disease by $20 \%$ [91]. However, we simultaneously observed an approximately 2-fold increase in hsCRP concentration in Greco-Roman wrestlers after 6-day normobaric hypoxia exposure (before IHT $1.45 \pm 0.33 \mathrm{mg} / \mathrm{dl}$, after IHT $2.89 \pm 0.54$ ) (unpublished data). The newest study indicates a significant correlation between serum hsCRP and the severity of coronary artery involvement [92]. Hence, further studies are recommended to be conducted on this issue in athletes.

\section{Conclusions and future directions}

The analysis of plasma cfDNA in relation to physical activity is currently being intensively studied, and this experience may determine the monitoring of overtraining-induced inflammation in the future.

Strenuous exercise, which consists of high-force eccentric exercises interspersed with long-duration endurance exercises at mild- to moderate-intensity work or regular high-intensity workouts, induces a slow and constant release of cfDNA. The elevated cfDNA level in both non-athletes and athletes is associated with markers of vascular endothelial dysfunction such as cytokines IL-1 $\beta$, IL-6 and TNF- $\alpha$, hsCRP, oxidized lipoproteins as well as reactive oxygen and nitrogen species, etc. The main source of cfDNA is apoptosis of endothelial cells and circulating endothelial progenitor cells as well as NETosis of immune cells which move toward the site of vascular injury.

Physical exercise in hypoxia (hypobaric or normobaric hypoxia) is considered as a therapeutic modality in delaying development of endothelial dysfunction and preserving vascular function. However, to develop appropriate hypoxia intervention guidelines, it is necessary to gain a deeper understating of how, when, and why hypoxia interferes with basic immune and repair mechanisms including EPC mobilization.

\section{Acknowledgments}

This work was funded by a grant from the Polish Ministry of Science and Higher Education 0047 RS3 201553.

\section{Conflict of interest}

The authors declare no conflict of interest.

\section{References}

1. Hirata Y, Nagata D, Suzuki E, Nishimatsu H, Suzuki J, Nagai R. Diagnosis and treatment of endothelial dysfunction in cardiovascular disease. Int Heart J 2010; 51: $1-6$.
2. Cao Y, Tao L, Yuan Y, et al. Endothelial dysfunction in adiponectin deficiency and its mechanisms involved. J Mol Cell Cardiol 2009; 46: 413-9.

3. Stępień M, Wlazeł RN, Paradowski M, et al. Serum concentrations of adiponectin, leptin, resistin, ghrelin and insulin and their association with obesity indices in obese normo- and hypertensive patients - pilot study. Arch Med Sci 2012; 8: 431-6.

4. Coelho M, Oliveira T, Fernandes R. Biochemistry of adipose tissue: an endocrine organ. Arch Med Sci 2013; 9: 191-200.

5. Griendling KK, FitzGerald GA. Oxidative stress and cardiovascular injury. Part I: Basic mechanisms and in vivo monitoring of ROS. Circulation 2003; 108: 1912-6.

6. Jylhävä J, Lehtimäki T, Jula A, et al. Circulating cell-free DNA is associated with cardiometabolic risk factors: the Health 2000 Survey. Atherosclerosis 2014; 233: 268-71.

7. Dimmeler S, Zeiher AM. Circulating microRNAs: novel biomarkers for cardiovascular diseases? Eur Heart J 2010; 31: 2705-7.

8. Volaklis KA, Tokmakidis SP, Halle M. Acute and chronic effects of exercise on circulating endothelial progenitors cells in healthy and diseased patients. Clin Res Cardiol 2013; 102: 249-57.

9. Rajendran P, Rengarajan T, Thangavel J, et al. The vascular endothelium and human diseases. Int J Biol Sci 2013; 9: 1057-69.

10. Cooke JP. Does ADMA cause endothelial dysfunction? Arterioscler Thromb Vasc Biol 2000; 20: 2032-7.

11. McDowell IF, Lang D. Homocysteine and endothelial dysfunction: a link with cardiovascular disease. J Nutr 2000; 130: 369S-72S.

12. Muniyappa R, Quon MJ. Insulin action and insulin resistance in vascular endothelium. Curr Opin Clin Nutr Metab Care 2007; 10: 523-30.

13. Chiu JJ, Lee PL, Chen CN, et al. Shear stress increases ICAM-1 and decreases VCAM-1 and E-selectin expressions induced by tumor necrosis factor-[alpha] in endothelial cells. Arterioscler Thromb Vasc Biol 2004; 24: 73-9.

14. Puz P, Lasek-Bal A, Ziaja D, Kazibutowska Z, Ziaja K. Inflammatory markers in patients with internal carotid artery stenosis. Arch Med Sci 2013; 9: 254-60.

15. Chalubinski M, Wojdan K, Dorantowicz R, Jackowska P, Gorzelak P, Broncel M. Comprehensive insight into immune regulatory mechanisms and vascular wall determinants of atherogenesis - emerging perspectives of immunomodulation. Arch Med Sci 2013; 9: 159-65.

16. Steinberg D, Witztum JL. Oxidized low-density lipoprotein and atherosclerosis. Arterioscler Thromb Vasc Biol 2010; 30: 2311-6.

17. Soumyarani VS, Jayakumari N. Oxidized HDL induces cytotoxic effects: implications for atherogenic mechanism. J Biochem Mol Toxicol 2014; 28: 481-9.

18. Sung DJ, So WY, Ryu HY, An HS, Cha KS. Induction of vasodilation by hydrogen peroxide and its application in exercise science. Biol Sport 2012; 29: 87-92.

19. Föstermann U. Nitric oxide and oxidative stress in vascular disease. Pflugers Arch 2010; 459: 923-39.

20. Lip GY, Blann A. von Willebrand factor: a marker of endothelial dysfunction in vascular disorders? Cardiovasc Res 1997; 34: 255-65.

21. Taniyama Y, Griendling KK. Reactive oxygen species in the vasculature: molecular and cellular mechanisms. Hypertension 2003; 42: 1075-81. 
22. Otocka-Kmiecik A, Mikhailidis DP, Nicholls SJ, Davidson M, Rysz J, Banach M. Dysfunctional HDL: a novel important diagnostic and therapeutic target in cardiovascular disease? Prog Lipid Res 2012; 51: 314-24.

23. Agouridis AP, Banach M, Mikhailidis DP. Dysfunctional high-density lipoprotein: not only quantity but first of all quality? Arch Med Sci 2015; 11: 230-1.

24. Dodani S, Dong L, Guirgis FW, Reddy ST. Carotid intima media thickness and low high-density lipoprotein (HDL) in South Asian immigrants: could dysfunctional HDL be the missing link? Arch Med Sci 2014; 10: 870-9.

25. Kasprzak MP, Iskra M, Majewski W, et al. PON1 status evaluation in patients with chronic arterial occlusion of lower limbs due to atherosclerosis obliterans. Arch Med Sci 2014; 10: 1101-8.

26. Toth PP, Barylski M, Nikolic D, Rizzo M, Montalto G, Banach $M$. Should low high-density lipoprotein cholesterol (HDL-C) be treated? Best Pract Res Clin Endocrinol Metab 2014; 28: 353-68.

27. Beiter T, Fragasso A, Hudemann J, et al. Neutrophils release extracellular DNA traps in response to exercise. J Appl Physiol 2014; 117: 325-33.

28. Borrisoff J, Joosen IA, Versteylen MO, et al. Elevated levels of circulating DNA and chromatin are independently associated with severe coronary atherosclerosis and a prothrombotic state. Arterioscler Thromb Vasc Biol 2013; 33: 2032-40.

29. Suzuki N, Kamataki A, Yamaki J, Homma Y. Characterization of circulating DNA in healthy human plasma. Clim Chim Acta 2008; 387: 55-9.

30. Breitbach S, Tug S, Simon P. Circulating cell-free DNA: an up-coming molecular marker in exercise physiology. Sports Med 2012; 42: 565-86.

31. Breitbach S, Sterzing B, Magallanes C, Tug S, Simon P. Direct measurement of cell-free DNA from serially collected capillary plasma during incremental exercise. J Appl Physiol (1985) 2014; 117: 119-30.

32. Fatouros IG, Destouni A, Margonis K, et al. Cell-free plasma DNA as a novel marker of aseptic inflammation severity related to exercise overtraining. Clin Chem 2006; 52: 1820-4.

33. Khoshkhahesh F, Siahkuhain M, Fisher G, NakhostinRoohi B. Influence of a low-dose COX-2 inhibitor drug on exercise-induced inflammation, muscle damage and lipid peroxidation. Biol Sport 2013; 30: 61-5.

34. Zapolska-Downar D, Sygitowicz G, Jarosz M. Znaczenie apoptozy w patogenezie miażdżycy. Kardiol Pol 2008; 66 (Suppl. 3): 347-57.

35. Angeli A, Minetto M, Dovio A, Paccotti P. The overtraining syndrome in athletes: a stress-related disorder. J Endocrinol Invest 2004; 27: 603-12.

36. Borges GF, Rama L, Pedreiro S, et al. Differences in plasma cytokine levels between elite kayakers and nonathletes. Biomed Res Int 2013; 2013: 370354.

37. Main LC, Dawson B, Grove JR, Landers GJ, Goodman C. Impact of training on changes in perceived stress and cytokine production. Res Sports Med 2009; 17: 121-32.

38. Marin DP, dos Santos Rde C, Bolin AP, Guerra BA, Hatanaka E, Otton R. Cytokines and oxidative stress status following a handball game in elite male players. Oxid Med Cell Longev 2011; 2011: 804873.

39. Ostrowski L, Rohde T, Asp S, Schjerling P, Pedersen BK. Pro- and anti-inflammatory cytokine balance in strenuous exercise in humans. J Physiol 1999; 515: 287-91.

40. Reinke S, Karhausen T, Doehner W, et al. The influence of recovery and training phases on body composition, peripheral vascular function and immune system of professional soccer players. PloS One 2009; 4: e4910.

41. Zembron-Lacny A, Slowinska-Lisowska M, Ziemba A. Integration of the thiol redox status with cytokine response to physical training in professional basketball players. Physiol Res 2010; 59: 239-45.

42. Ziemann E, Zembron-Lacny A, Kasperska A, et al. Exercise training-induced changes in inflammatory mediators and heat shock proteins in young tennis players. J Sports Sci Med 2013; 12: 282-9.

43. Smith LL. Tissue trauma: the underlying cause of overtraining syndrome? J Strength Cond Res 2004; 18: 185-93.

44. Durstine JL, Grandjean PW, Davis PG, Ferguson MA, Alderson NL, DuBose KD. Blood lipid and lipoprotein adaptations to exercise: a quantitative analysis. Sports Med 2001; 31: 1033-62.

45. Ribeiro F, Alves AJ, Duarte JA, Oliveira J. Is exercise training an effective therapy targeting endothelial dysfunction and vascular wall inflammation? Int J Cardiol 2010; 141: 214-21.

46. Turowski D, Pokrywka A, Braksator W, Rysz J, Banach M. Strength-endurance training may promote pro-atherogenic changes in lipoprotein profile of adolescent rowers. Atherosclerosis 2015; 241: e186-7.

47. Petersen AM, Pedersen BK. The anti-inflammatory effect of exercise. J Appl Physiol 2005; 98: 1154-62.

48. Gomes VA, Casella-Filho A, Chagas AC, Tanus-Santos JE. Enhanced concentrations of relevant markers of nitric oxide formation after exercise training in patients with metabolic syndrome. Nitric Oxide 2008; 19: 345-50.

49. Hambrecht R, Walther C, Möbius-Winkler S, et al. Percutaneous coronary angioplasty compared with exercise training in patients with stable coronary artery disease: a randomized trial. Circulation 2004; 109: 1371-8.

50. Laughlin MH, Joseph B. Wolfe Memorial Lecture. Physical activity in prevention and treatment of coronary disease: the battle line is in exercise vascular cell biology. Med Sci Sports Exerc 2004; 36: 352-62.

51. Petibois C, Cassaigne A, Gin H, Déléris G. Lipid profile disorders induced by long-term cessation of physical activity in previously highly endurance-trained subjects. J Clin Endocrinol Metab 2004; 89: 3377-84.

52. Maron BJ, Shen WK, Links MS, et al. Efficacy of implantable cardioverter-defibrillators for the prevention of sudden death in patients with hypertrophic cardiomyopathy. N Engl J Med 2000; 342: 365-73.

53. Suarez-Mier MP, Aguilera B, Mosquera RM, Sánchez-deLeón MS. Pathology of sudden death during recreational sports in Spain. Forensic Sci Int 2013; 226: 188-96.

54. De Van AE, Seals DR. Vascular health in the ageing athlete. Exp Phsyiol 2012; 97: 305-10.

55. Agrotou S, Karatzi K, Papamichael C, et al. Effects of chronic anaerobic training on markers of sub-clinical atherosclerosis. Hellenic J Cardiol 2013; 54: 178-85.

56. Gardner AW, Parker DE, Montgomery PS, et al. Greater endothelial apoptosis and oxidative stress in patients with peripheral artery disease. Int J Vasc Med 2014; 2014: 160534.

57. Robaye B, Mosselmans R, Fiers W, Dumont JE, Galand P. Tumour necrosis factor induces apoptosis (programmed cell death) in normal endothelial cells in vitro. Am J Pathol 1991; 138: 447-53.

58. Zhang $\mathrm{H}$, Park Y, Wu J, et al. Role of TNF $\alpha$ in vascular dysfunction. Clin Sci (Lond) 2009; 116: 219-30.

59. Zahran N, Sayed A, William I, Mahmoud O, Sabry O, Rafaat M. Neutrophil apoptosis: impact of granulocyte macrophage colony stimulating factor on cell survival 
and viability in chronic kidney disease and hemodialysis patients. Arch Med Sci 2013; 9: 984-9.

60. Zembron-Lacny A, Ziemann E, Kasperska A, et al. Association between cytokine activity and body composition in highly trained athletes. Medicina dello Sport 2013; 66: 199-209.

61. Raglin J, Wilson G. Overtraining and staleness in ath letes. In: Emotions in sports. Hanin YL (ed.). Human Kinetics, Champaign (IL) 2000; 191-207.

62. Goldmann O, Medina E. The expanding world of extracellular traps: not only neutrophils but much more. In NETosis. At the intersection of cell biology, microbiology, and immunology. Kaplan MJ. (ed.). The Round Thing 2014

63. Wang Y, Li M, Stadler S, et al. Histone hypercitrullination mediates chromatin decondensation and neutrophil extracellular trap formation. J Cell Biol 2009; 184: 205-13.

64. Fuchs TA, Abed U, Goosmann C, et al. Novel cell death program leads to neutrophil extracellular traps. J Cell Biol 2007; 176: 231-41.

65. Martinelli S, Urosevic M, Daryadel A, et al. Induction of genes mediating interferon-dependent extracellular trap formation during neutrophil differentiation. J Biol Chem 2004; 279: 44123-32.

66. Yousefi S, Mihalache C, Kozlowski E, Schmid I, Simon HU. Viable neutrophils release mitochondrial DNA to form neutrophil extracellular traps. Cell Death Differ 2009; 16: 1438-44.

67. Ramos-Kichik V, Mondragon-Flores R, Mondragon-Castelan $M$, et al. Neutrophil extracellular traps are induced by Mycobacterium tuberculosis. Tuberculosis (Edinb.) 2009; 89: 29-37.

68. Brinkmann V, Reichard U, Goosmann C, et al. Neutrophi extracellular traps kill bacteria. Science 2004; 303: 1532-5.

69. Brinkmann V, Zychlinsky A. Beneficial suicide: why neu trophils die to make NETs. Nat Rev Microbiol 2007; 5: 577-82.

70. Guimaraes-Costa AB, Nascimento MT, Froment GS, et al. Leishmania amazonensis promastigotes induce and are killed by neutrophil extracellular traps. Proc Natl Acad Sci USA 2009; 106: 6748-53.

71. Lauth $X$, von Kockritz-Blickwede M, McNamara CW, et al. M1 protein allows group A streptococcal survival in phagocyte extracellular traps through cathelicidin inhibition. J Innate Immun 2009; 1: 202-14.

72. Pilsczek FH, Salina D, Poon KK, et al. A novel mechanism of rapid nuclear neutrophil extracellular trap formation in response to Staphylococcus aureus. J Immunol 2010; 185: 7413-25.

73. Hakkim A, Fuchs TA, Martinez NE, et al. Activation of the Raf-MEK-ERK pathway is required for neutrophil extracellular trap formation. Nat Chem Biol 2011; 7: 75-7.

74. Araźna M, Pruchniak MP, Demkow U. Reactive oxygen species, granulocytes, and NETosis. Adv Exp Med Biol 2015; 836: 1-7.

75. Chow OA, von Kockritz-Blickwede $M$, Bright AT, et al. Statins enhance formation of phagocyte extracellular traps. Cell Host Microbe 2010; 8: 445-54.

76. Clark SR, Ma AC, Tavener SA, et al. Platelet TLR4 activates neutrophil extracellular traps to ensnare bacteria in septic blood. Nat Med 2007; 13: 463-9.

77. Brinkman V, Zychlinsky A. Neutrophil extracellular traps: is immunity the second function of chromatin? J Cell Biol 2012; 198: 773-83.

78. Schwarzenbach H, Nishida N, Calin GA, Pantel K. Clinical relevance of circulating cell-free microRNAs in cancer. Nat Rev Clin Oncol 2014; 11: 145-56.
79. Adams V, Linke A, Breuckmann F, et al. Circulating progenitor cells decrease immediately after marathon race in advanced-age marathon runners. Eur J Cardiovasc Prev Rehabil 2008; 15: 602-7.

80. Koutroumpi M, Dimopoulos S, Psarra K, Kyprianou T, Nanas S. Circulating endothelial and progenitor cells: evidence from acute and long-term exercise effects. World J Cardiol 2012; 26: 312-26.

81. Schlager O, Giurgea A, Schuhfried O, et al. Exercise training increases endothelial progenitor cells and decreases asymmetric dimethylarginine in peripheral arterial disease: a randomized controlled trial. Atherosclerosis 2011; 217: 240-8.

82. Spiropoulos A, Goussetis E, Margeli A, et al. Effect of inflammation induced by prolonged exercise on circulating erythroid progenitors and markers of erythropoiesis. Clin Chem Lab Med 2010; 48: 199-203.

83. Wahl P, Bloch W, Schmidt A. Exercise has positive effect on endothelial progenitors cells, which could be necessary for vascular adaptation processes. Int J Sports Med 2007; 28: 374-80.

84. Ciulla MM, Giorgetti A, Lazzari L, et al. High-altitude trekking in the Himalayas increases the activity of circulating endothelial cells. Am J Hematol 2005; 79: 76-8.

85. Hristov M, Weber C. Endothelial progenitor cells in vascular repair and remodeling. Pharmacol Res 2008; 58 : 148-51.

86. Mancuso P, Peccatori F, Rocca A, et al. Circulating endothelial cell number and viability are reduced by exposure to high altitude. Endothelium 2008; 15: 53-8.

87. Möhlenkamp S, Lehmann N, Breuckmann F, et al. Running: the risk of coronary events. Prevalence and prognostic relevance of coronary atherosclerosis in marathon runners. Eur Heart J 2008; 29: 1903-10.

88. Vogt $M$, Hoppeler $H$. Is hypoxia training good for muscles and exercise performance? Porg Cardiovasc Dis 2010; 52: 525-33.

89. Bailey DM, Davies B, Baker J. Training in hypoxia: modulation of metabolic and cardiovascular risk factors in men. Med Sci Sports Exerc 2000; 32: 1058-66.

90. Haufe S, Wiesner S, Engeli S, Luft FC, Jordan J. Influence of normobaric hypoxia training on metabolic risk markers in human subjects. Med Sci Sports Exerc 2008; 40: 1939-44.

91. Graham I, Atar D, Borch-Johnsen K, et al. European guidelines on cardiovascular disease prevention in clinical practice - short version [Polish]. Kardiol Pol 2008; 66: 4 (Suppl. 1).

92. Piranfar MA. The Correlation between high-sensitivity C-reactive protein (hSCRP) serum levels and severity of coronary atherosclerosis. Int Cardiovasc Res J 2014; 8: 6-8. 